F.R. Tay ${ }^{1,2 *}$, D.H. Pashley ${ }^{1}$, N. Hiraishi², S. Imazato ${ }^{3}$, F.A. Rueggeberg ${ }^{1}$, U. Salz ${ }^{4}$, J. Zimmermann ${ }^{4}$, and N.M. King ${ }^{2}$

${ }^{1}$ School of Dentistry, Medical College of Georgia, Augusta, GA, USA; ${ }^{2}$ Paediatric Dentistry and Orthodontics, Faculty of Dentistry, The University of Hong Kong, Pokfulam, Prince Philip Dental Hospital, 34 Hospital Road, Hong Kong SAR, China; ${ }^{3}$ Osaka University Graduate School of Dentistry, Osaka, Japan; and ${ }^{4}$ Research and Development, Ivoclar-Vivadent AG, Schaan, Liechtenstein; *corresponding author, franklintay@gmail.com

J Dent Res 84(10):891-896, 2005

\section{Tubular Occlusion Prevents Water-treeing and Through- and-Through Fluid Movement in a Single-bottle, One-step Self-etch Adhesive Model}

\section{INTRODUCTION}

Water entrapment occurs at resin-dentin interfaces of one-step self-etch adhesives. We hypothesized that by preventing water fluxes from dentin, any water entrapment would be attributed to incomplete removal of adhesive solvents. We tested this hypothesis by bonding to transparent carious dentin containing occluded dentinal tubules. An experimental single-bottle, one-step self-etch adhesive was applied to flat surfaces of caries-affected dentin surrounded by sound dentin, with or without pulpal pressure. Resin-dentin interfaces were examined with TEM after silverimpregnation. Although caries-affected dentin was highly porous, adhesive layers were devoid of silver deposits when tubules were occluded. Conversely, variable extents of water-treeing and water-droplets were identified from adhesive layers in bonded sound dentin. Water-treeing and water-droplet formation, being manifestations of evaporative and convective water fluxes, can be eliminated during bonding to occluded transparent carious dentin. However, the highly porous nature of this clinically relevant substrate after bonding may lead to potentially undesirable consequences.

KEY WORDS: fluid transudation, one-step selfetch, water-treeing, sound dentin, caries-affected dentin.

Received October 27, 2004; Last revision May 25, 2005; Accepted June 30, 2005
D entinal fluid transudation across simplified dentin adhesives has been shown to occur when they were bonded to non-carious, deep, vital human dentin (Chersoni et al., 2004; Tay et al., 2004a). This phenomenon could be duplicated in vitro with the use of bonded, extracted human teeth (Elgalaid et al., 2004). Since single-step self-etch adhesives lack solventfree resin coatings (Cheong et al., 2003), they behave as permeable membranes that permit rapid through-and-through water movement across the polymerized adhesives (Tay et al., 2004b). Entrapment of water droplets that emerged from the adhesive surfaces by slow-polymerizing, chemically cured resin composites (Tay et al., 2003a; Carvalho et al., 2004) accounted for the apparent incompatibility when these composites were coupled to acidic adhesives in the presence of non-amine-type ternary catalysts (Suh et al., 2003).

Ultrastructually, water entrapment in one-step self-etch adhesives is visualized as water-filled channels (i.e., water trees; Tay and Pashley, 2003). With single-bottle versions of such adhesives, additional discrete water droplets (Tay et al., 2003b; De Munck et al., 2005) were identified, and were surmised to represent phase separation of water after evaporation of volatile solvent (Van Landuyt et al., 2005). Together with nanoleakage within the hybrid layers of self-etch adhesives, these water-rich interfacial regions represent potential sites from which bond degradation may initiate (Hashimoto et al., 2004a; Carvalho et al., 2005).

Since all the above observations were obtained from sound coronal dentin, it was difficult for us to resolve whether the entrapped water originated from water-containing self-etch adhesives or from the hydrated dentin. Theoretically, water emanating from dentinal tubules (i.e., convective water flux; Pashley et al., 1981) should be minimal when mild self-etch adhesives are applied to smear-layer-covered dentin. However, evaporative water flux may still occur through the adhesive-infiltrated smear plugs as adhesive solvents are removed with air-blasts (Goodis et al., 1990, Matthews et al., 1993). We hypothesized that by eliminating convective and evaporative water fluxes (Sidhu et al., 2004) from dentin substrates (Lee et al., 2003), any water entrapment within the adhesive should be attributed to the retention of water derived from one-step self-etch adhesives.

This hypothesis is testable by the use of an adhesive with known water concentration, and transparent carious dentin as a bonding substrate, since the dentinal tubules in the latter are heavily occluded with intratubular mineral deposits (Zheng et al., 2003). Although completely dehydrated sound dentin could be used, we considered hydrated caries-affected dentin to be a more clinically relevant bonding substrate, since the results could be compared with the adjacent hydrated sound dentin derived from the same specimen. Thus, the null hypothesis tested was that there is no difference in 
the manifestation of water-rich interfacial regions stained by silver in resin-dentin interfaces created with an experimental single-bottle one-step self-etch adhesive in sound or transparent carious dentin.

\section{MATERIALS \& METHODS}

Twenty human third molars with extensive occlusal caries were collected after informed consent had been obtained from patients aged between 39 and $51 \mathrm{yrs}$, under a protocol approved by the Institutional Review Board of the Medical College of Georgia. These teeth were stored in $0.5 \%$ chloramine $\mathrm{T}$ at $4^{\circ} \mathrm{C}$ and were used within 2 mos after extraction.

\section{Tooth Preparation}

Access to carious coronal dentin was achieved with a tungsten carbide bur in a high-speed handpiece under water cooling. Since the effects of caries-indicating dyes on water flux are unknown, soft caries-infected dentin was removed by means of a slow-speed handpiece equipped with a polymer bur (SmartPrep, SS White Burs, Inc., Lakewood, NJ, USA) that reportedly has a hardness similar to that of caries-affected dentin (Boston, 2003). Two or 3 polymer burs were used for each tooth, until the burs dulled and vibrated on reaching the hard, discolored caries-affected dentin.

The bulk of the occlusal hard tissue above the cavity floor was removed with a slow-speed saw (Isomet, Buehler Ltd., Lake Bluff, IL, USA) under water irrigation. Additional abrading of the remaining hard tissues was performed with 180-grit silicon carbide (SiC) paper. This created a flat surface with a zone of hard cariesaffected dentin surrounded by peripheral sound dentin, at a level that was slightly below the original cavity floor generated by the polymer burs. Teeth with pulpal exposures were discarded, resulting in 11 intact specimens for the study.

\section{Experimental Adhesive}

An experimental unfilled, single-bottle, one-step self-etch adhesive with known water and acetone concentrations was formulated, since it is impossible to control the hydrolysis of ester-linkages in 2-hydroxyethyl methacrylate (HEMA) or acidic resin monomers when water is pre-included in single-bottle self-etch adhesives (Moszner et al., 1999; Nishiyama et al., 2004).

The experimental adhesive $(\mathrm{pH}=1.58)$ consisted of $(\mathrm{wt} \%)$ : 4methacryloxyethyltrimellitic anhydride [4-META] (17\%), 1,6-bis[2-methacryloyloxyethoxycarbonylamino]-2,4,4-trimethylhexane [UDMA] (14\%), glutaraldehyde (4\%), camphorquinone $(0.3 \%)$, tertiary amine [ethyl 4-(dimethylamino) benzoate] $(0.5 \%)$, butylated hydroxytoluene $(0.03 \%)$, acetone $(39.17 \%)$, and water (25\%). Glutaraldehyde was included and HEMA was excluded to simulate a commercially available adhesive (iBond, HeraeusKulzer, Hanau, Germany). To prevent hydrolysis of 4-META and UDMA into lower-molecular-weight, non-functional components and methacrylic acid during shipment, we initially segregated the glutaraldehyde and water from the other components. The reconstituted single-bottle adhesive was allowed to stand for 60 min, to convert the 4-META into its functional form, 4methacryloxyethyltrimellitic acid. The adhesive was used within 1 mo after reconstitution and was stored at $4{ }^{\circ} \mathrm{C}$ after each use.

\section{Substrate Characterization}

Variations in caries-affected dentin exist in their degree of mineralization, porosities, and nanohardness. Since tubular occlusion was the primary concern, the carious dentin that remained after polymer bur excavation and $\mathrm{SiC}$ paper abrasion was examined with transmission electron microscopy (TEM). Substrate characterization was based upon the absence of structurally disorganized (i.e., caries-infected) dentin containing bacteria in distorted tubules with minimal intratubular mineral deposits, and the presence of intact tubules occluded with intratubular minerals that are characteristic of the transparent zone in carious human dentin (Marshall et al., 2001).

Three specimens were randomly selected, and a 2-mm-thick section was prepared from each tooth by an additional cut made parallel to the abraded surface. The 2 undemineralized disks were sonicated in 0.1 M cacodylate buffer ( $\mathrm{pH} 7.4$ ), and then fixed, dehydrated, and embedded in epoxy resin for TEM (Tay et al., 1999). Regions containing the carious dentin were retrieved for the preparation of 90 - to 120 -nm-thick sections. Unstained sections were examined under a TEM (EM208S, Philips, Eindhoven, The Netherlands) operating at $80 \mathrm{kV}$.

\section{Bonding Procedures}

The remaining specimens were sectioned $3 \mathrm{~mm}$ below the cementoenamel junction. After the pulpal tissues were removed, 4 crown segments containing carious dentin surrounded by adjacent sound dentin were cemented to Plexiglass slabs penetrated by a stainless steel tube. This permitted filling of the pulp chamber with water via a piece of plastic tubing connected to a syringe barrel (Pashley and Depew, 1986). To permit evaporative water flux without convective water movement, we positioned the crown segment at the same level as the water syringe, producing $0 \mathrm{~cm}$ of water pressure. When air blasts are used to evaporate adhesive solvents, any water movement is due only to evaporation. The remaining 4 crown segments were bonded under dentin perfusion to permit both convective and evaporative water fluxes during bonding, by raising the water syringe to deliver $20 \mathrm{~cm}$ of water pressure.

Three consecutive coats of the experimental adhesive were applied to each crown segment with agitation and a dwelling time of $30 \mathrm{sec}$. The adhesive solvent was evaporated with moisture-free air blown $0.25 \mathrm{~m}$ above the bonding surface. The adhesive was light-cured for $20 \mathrm{sec}$ in a light-emitting-diode curing unit (LE Demetron 1, Sybron Kerr, Orange, CA, USA) operated at 925 $\mathrm{mW} / \mathrm{cm}^{2}$. To enable the bonded carious dentin to be discerned from bonded sound dentin during laboratory processing, we coupled a 2-mm-thick layer of translucent, microfilled composite (EPIC-TMPT, Parkell Inc., Farmingdale, NY, USA) to the bonded dentin and light-cured it for $40 \mathrm{sec}$.

One-mm-thick sections containing only composite-coupled sound dentin, or regions with composite-coupled carious dentin, were made perpendicular to the resin-dentin interfaces. One section of each category was retrieved from each tooth. The sections were immersed in a $50 \mathrm{wt} \%$ ammoniacal silver nitrate tracer solution for $24 \mathrm{hrs}$, for detection of potential water-rich regions within the resin-dentin interfaces via the reduction of the silver-ion complexes into silver deposits, according to a tracerimpregnation protocol (Tay and Pashley, 2003). The silverimpregnated specimens were processed for TEM examination.

\section{Statistical Analysis}

The silver distribution within the adhesive layers was examined with an image analysis program (Scion Image, Scion Corp., Frederick, MD, USA), with 8 sections used from each of the 4 bonded groups (sound vs. carious dentin; 0 vs. $20-\mathrm{cm}$ water pressure). Since the data were not normally distributed, they were analyzed by Kruskal-Wallis ANOVA on ranks and Dunn's multiple-comparison tests at $\alpha=0.05$. 

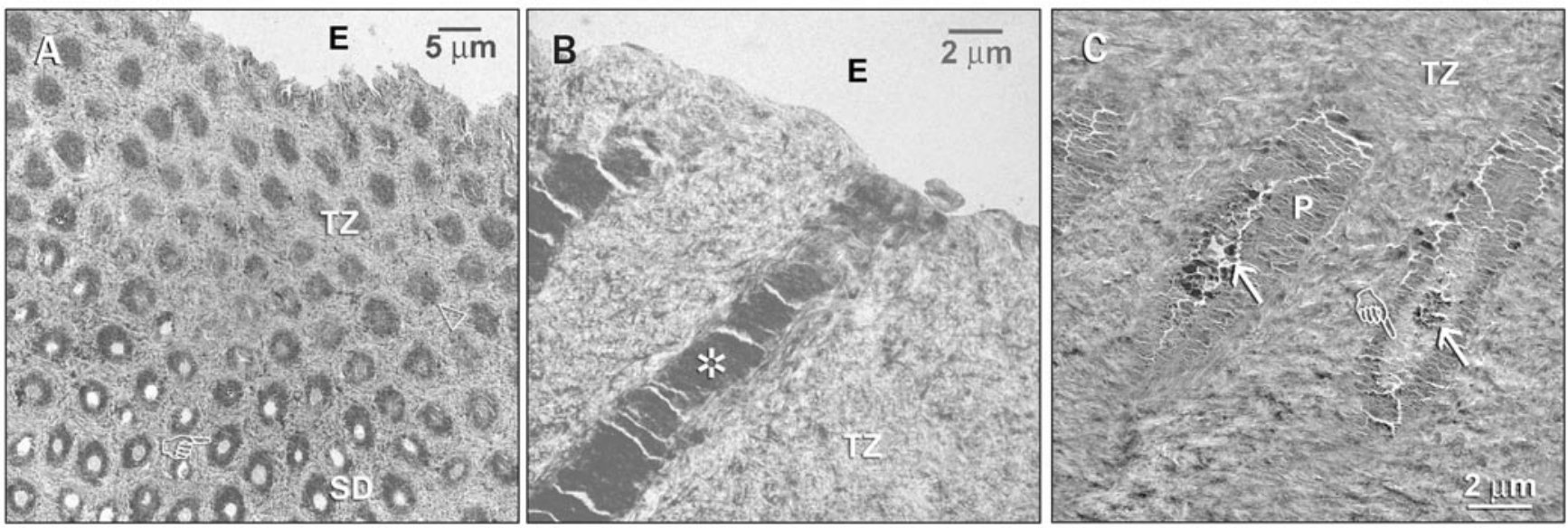

Figure 1. TEM characterization of the unbonded, unstained, undemineralized, epoxy-resin-infiltrated, carious dentin substrate that remained after polymer bur amputation and silicon carbide paper abrasion. E: epoxy resin. (A) A low-magnification view of the first specimen, showing that the abraded surface corresponded with the transparent zone of carious dentin (TZ; i.e., caries-affected dentin). Transverse sectioning of the dentinal tubules in this zone indicated that the dentinal tubules were completely occluded by intratubular mineral deposits (open arrowhead). In contrast, dentinal tubules in the underlying sound dentin (SD) were either completely empty or contained remnant tubular contents that did not occlude the tubules (pointer). (B) A high-magnification view of the second specimen, showing the occlusion of dentinal tubules with fine, electron-dense intratubular mineral deposits (asterisk). Peritubular dentin cannot be readily discerned from the intertubular dentin in this specimen. (C) A highmagnification view of the transparent zone (TZ) from the third specimen. The dentinal tubules were occluded within intratubular mineral deposits (pointer) that can be distinguished from the peritubular dentin (P). In addition, larger discrete electron-dense caries crystals (arrows) can be identified within the tubular lumen.
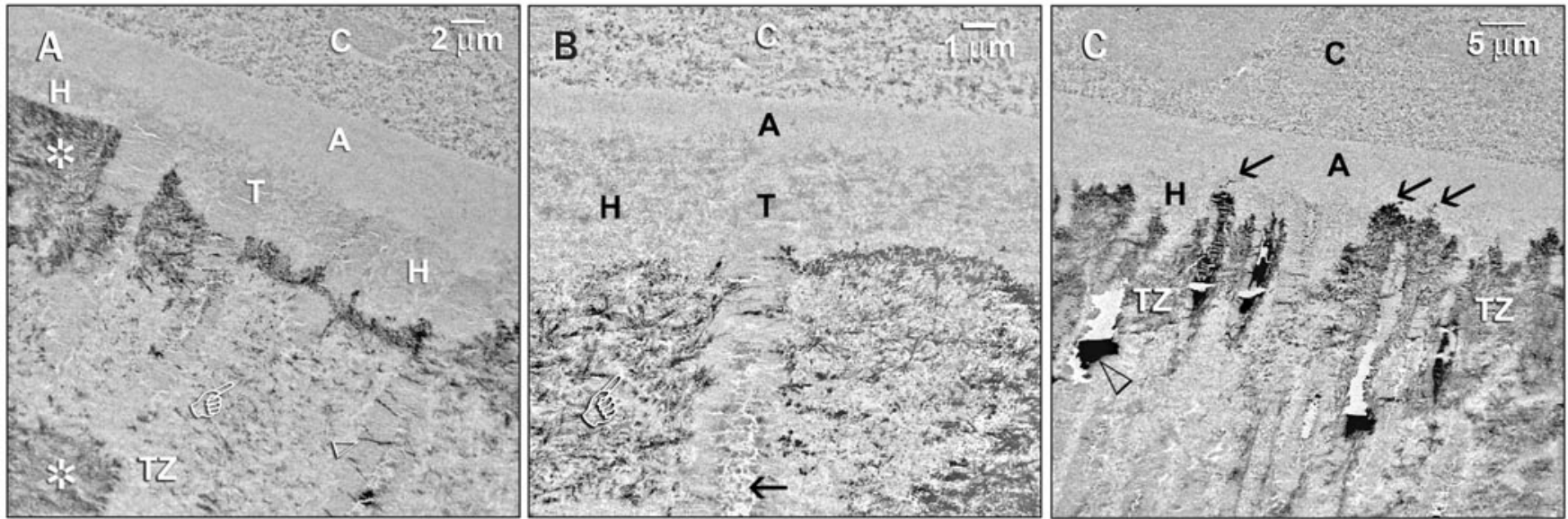

Figure 2. TEM micrographs of unstained, undemineralized, silver-impregnated sections, illustrating the application of the experimental single-bottle, one-step self-etch adhesive to carious dentin that remained after polymer bur amputation and $\mathrm{SiC}$ paper abrasion. $\mathrm{C}$, resin composite; $\mathrm{A}$, adhesive layer; $\mathrm{H}$, hybrid layer. (A) A low-magnification view of a specimen that was bonded at $0 \mathrm{~cm}$ of $\mathrm{H}_{2} \mathrm{O}$ pressure. The hybrid layer varied from 2-5.5 $\mu \mathrm{m}$ thick. Both the hybrid layer and the adhesive layer were devoid of silver deposits. In contrast, the underlying transparent zone of caries-affected dentin (TZ) was highly porous, with discrete islands of heavy silver deposits (asterisks), and zones of reticular silver deposits (pointer) within the intertubular dentin, as well as within the intratubular mineral deposits located beneath the hybrid layer (open arrowhead). Dentinal tubular orifices (T) were completely occluded with intratubular mineral deposits. (B) A higher-magnification view of another carious dentin specimen that was bonded at $0 \mathrm{~cm}$ of $\mathrm{H}_{2} \mathrm{O}$ pressure, showing a well-sealed hybrid layer and an adhesive layer devoid of silver deposits. The highly porous nature of the transparent zone of carious dentin can be distinguished by the reticular streaks of silver deposits (pointer). The tubular orifice (T) was also completely occluded within intratubular minerals. Additional discrete caries crystals (arrow) can be identified farther down the dentinal tubule. (C) A specimen that was bonded under the application of $20 \mathrm{~cm}$ of water pressure. Some nanoleakage can be identified within the hybrid layer (arrows). However, that was relatively mild compared with the heavy reticular silver deposits identified from the transparent zone of carious dentin (TZ). Some of the tubules, probably from a region of sound dentin, were patent and were heavily filled with silver deposits after dentin perfusion. In contrast, the adhesive layer was completely devoid of silver.

\section{RESULTS}

Examination of unbonded carious dentin substrate confirmed that, in the transparent zone of carious dentin (Fig. 1A), dentinal tubules were occluded with fine intratubular mineral deposits (Fig. 1B) or in combination with discrete caries crystals (Daculsi et al., 1987) (Fig. 1C).
When bonding was performed on caries-affected dentin, both the hybrid layers ( $c a$. 2-6 $\mu \mathrm{m}$ thick) and adhesive layers were free of silver deposits in specimens bonded at $0 \mathrm{~cm}$ of water pressure (Figs. 2A, 2B). At $20 \mathrm{~cm}$ of water pressure, the adhesive layers were also devoid of silver deposits, although some nanoleakage could be identified in hybrid layers (Fig. 2C). Conversely, the underlying dentin substrates were highly 



Figure 3. TEM micrographs of unstained, undemineralized, silver-impregnated sections, illustrating the application of the experimental single-bottle, one-step self-etch adhesive to sound dentin (SD). Bonding was performed under $\mathrm{O} \mathrm{cm}$ of $\mathrm{H}_{2} \mathrm{O}$ pressure to permit only evaporative water flux. $\mathrm{C}$, resin composite $A$, adhesive layer; $H$, hybrid layer. (A) Bonded sound dentin taken from the same tooth as the bonded carious dentin in Fig. 2A. The 1- $\mu$ m-thick hybrid layer was completely occupied by reticular silver deposits (nanoleakage). A layer of silver-impregnated water channels (i.e., water trees) can be seen arising from the surface of the hybrid layer and extending into the adhesive layer (pointer). Additional isolated silver grains (open arrowhead) can be discerned within the adhesive layer. (B) Bonded sound dentin taken from the same tooth as the bonded carious dentin in Fig. 2B. Apart from the presence of extensive nanoleakage within the hybrid layer $(\mathrm{H})$, and the water trees that extended from the surface of the hybrid layer (pointer), extensive water-treeing could be identified throughout the adhesive lopen arrowhead). The water trees that were in contact with the resin composite permitted through-andthrough water movement and resulted in the entrapment of water blisters along the adhesive-composite interface (open arrow). These relatively smaller water blisters were completely filled with silver deposits.
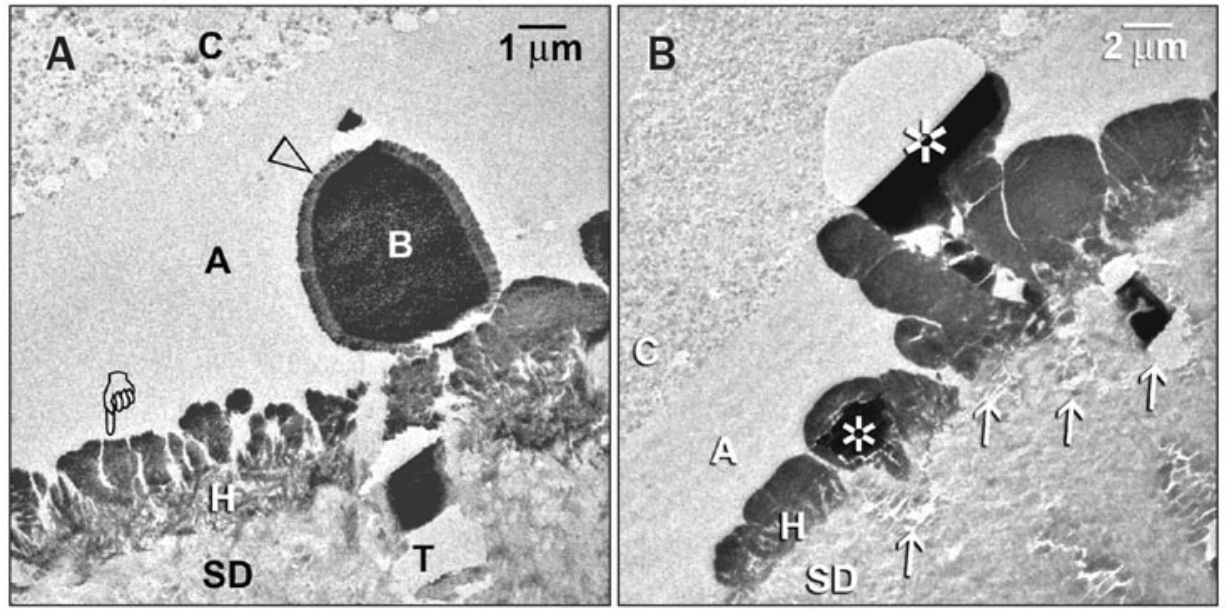

Figure 4. TEM micrographs of unstained, undemineralized, silver-impregnated sections, illustrating the application of the experimental single-bottle, one-step self-etch adhesive to sound dentin (SD). Bonding was performed under $20 \mathrm{~cm}$ of $\mathrm{H}_{2} \mathrm{O}$ pressure to permit both convective and evaporative water fluxes. $\mathrm{C}$, resin composite; $A$, adhesive layer; $H$, hybrid layer. (A) Similar to the specimens bonded without dentin perfusion, the hybrid layer was extensively filled with silver deposits, with water derived from the evaporative water flux extending into the adhesive layer as a layer of water trees (pointer). The effect of convective water flux can be seen as the expression of a large water droplet (B), completely filled with silver deposits, from a patent dentinal tubular orifice $(T)$ into the adhesive layer. Secondary water trees (open arrowhead) can be seen radiating from the circumference of the water droplet. (B) Bonded sound dentin taken from the same specimen from which Fig. $2 \mathrm{C}$ was taken. Extensive convective water flux from the array of dentinal tubules (arrows) resulted in the formation of water droplets (asterisk). Through-and-through water movement resulted in the extension of a large water blister into the resin composite. This water blister was partially filled with silver and was retained by the polymerizing composite during light-activation. porous and exhibited extensive silver deposition.

Hybrid layers created in adjacent sound dentin (ca. $1 \mu \mathrm{m}$ thick) were heavily impregnated with reticular silver deposits. In the absence of water pressure, water trees were mostly identified along the hybrid layer surface (Fig. 3A), and occasionally throughout the adhesive layer (Fig. 3B). With the application of water pressure, additional water droplets emanating from patent tubular orifices were observed (Fig. 4A). The convective flux also induced through-andthrough water movement, resulting in the manifestation of large blisters within the adhesive-composite interface (Fig. 4B).

Percentages of silver distribution within adhesive layers ( $c a$. $2-8 \mu \mathrm{m}$ thick) were $0.0 \pm 0.0 \%$ and $0.6 \pm 1.2 \%$ for carious dentin bonded without and with pulpal pressure, and $30.4 \pm 22.9 \%$ and $38.2 \pm 20.0 \%$ for sound dentin bonded without and with pulpal pressure. Significant differences were observed among the sound dentin groups $v s$. the carious dentin groups $(\mathrm{P}<0.001)$. No difference could be seen when sound/carious dentin samples were bonded with or without pulpal pressure $(\mathrm{P}>0.05)$.

\section{DISCUSSION}

Since water-containing, methacrylate-based, pre-mixed self-etch adhesives are prone to hydrolysis when stored at elevated temperatures (Nishiyama et al., 2004), we formulated an experimental adhesive in which ongoing hydrolytic degradation was monitored, at different storage times and temperatures, with nuclear magnetic resonance spectroscopy and microtensile bond strength evaluations. The negligible hydrolytic degradation observed after one-month storage at $4^{\circ} \mathrm{C}$ (Salz et al., unpublished results) enabled us to conclude that the water-trees and water droplets within the adhesive layers of bonded sound dentin were not nonpolymerizable hydrolytic products, such as trimellitic acid or ethylene glycol. In the absence of water-rich regions in the bonded carious dentin, we can reject the null 
hypothesis and assert that, at least for the experimental adhesive investigated, the ultrastructural manifestations of water-rich interfacial regions in bonded sound dentin did not represent phase separation of water (24 vol\%) from unpolymerized resin monomers $(28.4$ vol\%) after acetone evaporation (47.6 vol\%).

Our results indicated that evaporative water flux was responsible for the formation of water trees, while convective water flux additionally contributed to the expression of water droplets from dentinal tubules. Although water-treeing could be identified throughout the adhesive layer in bonded sound dentin (Fig. 3B), they were predominantly seen as a relatively thick layer over the hybrid layer surface. These water trees were also continuous with silver deposits that occupied the interfibrillar spaces of hybrid layers (Fig. 3A). Although air-drying is mandatory for removing adhesive solvents, it also induces evaporative water loss from dentin before self-etch and etchand-rinse adhesives are polymerized (Hashimoto et al, 2004b). In the presence of smear plugs within tubular orifices, water probably passes through the channels of least resistance, along the smear plugs and peritubular dentin (Carvalho et al., 2005) into the interfibrillar spaces of intertubular dentin, and is subsequently trapped as water vapor within the adhesive. In the case of convective water flux, $20 \mathrm{~cm} \mathrm{H}_{2} \mathrm{O}$ water pressure plus evaporative water loss, more water would pass through the smear plugs and adhesive, resulting in water blebbing in the adhesive layer, wherein they undergo phase separation into spherical water droplets within the solvent-sparse, comparatively hydrophobic "all-in-one" adhesive. Concomitant evaporative water flux accounts for primary water-treeing over the hybrid layer surface, as well as secondary water-treeing around the circumference of these water droplets (Fig. 4A).

It is remarkable that, in the absence of water fluxes from transparent carious dentin, an excellent seal could be established along the bonded interfaces. Even when the transparent carious dentin was bonded under $20 \mathrm{~cm}$ of water pressure, far fewer silver deposits were seen within these hybrid layers when compared with those in sound dentin. The result is an excellent resin seal on the surface of a highly porous, incompletely infiltrated bonding substrate. Although these hybrid layers were thicker than those created in sound dentin (Yoshiyama et al., 2002), the expected bond strength to the caries-affected dentin would be lower than the corresponding bond strength to sound dentin, since it is unlikely that any adhesive can diffuse through a zone of partially demineralized carious dentin that may be several hundred micrometers thick. In the broadest sense, this scenario resembles a much amplified version of an incompletely infiltrated hybrid layer produced by an etch-and-rinse adhesive in sound dentin. Similar to incompletely infiltrated sound dentin, the non-infiltrated caries-affected dentin may undergo self-destruction via the release of endogenous matrix metalloproteinases (Pashley et al., 2004). There is also immuohistochemical evidence suggesting that the antigenicities of type I collagen and proteoglycans are masked in cariesaffected dentin (Breschi et al., unpublished results) that may prevent the potential for intrafibrillar remineralization of the partially demineralized collagen matrices in caries-affected dentin.

In conclusion, the results of this work provide reassurance of the validity of the concept of simultaneous etching and priming in self-etch adhesives. Although tubular occlusion did prevent water-treeing and through-and-through fluid movement in our one-step self-etch adhesive model, it is unrealistic that, clinically, one can bond only to transparent carious dentin without involving sound dentin. A likely scenario is that one may encounter a gradual transition from a strongly bonded but permeable interface to a weakly bonded (Yoshiyama et al., 2002) but relatively impermeable interface (Lee et al., 2003), as the bonding substrate shifts from sound to caries-affected dentin along the cavity floor. Thus, the use of two-step selfetch adhesives that exhibit higher bond strengths and less permeability appears to be a more prudent approach in the execution of the self-etching technique.

\section{ACKNOWLEDGMENTS}

The experimental single-bottle one-step adhesive used in this study was a generous gift from Ivoclar-Vivadent. The SmartPrep polymer burs were generous gifts from SS White Burs, Inc. We thank Delia Yeung for technical assistance with TEM laboratory resin embedding. This study was supported by grant 10204604/07840/08004/324/01, Faculty of Dentistry, the University of Hong Kong, and by grants DE 014911 and DE 015306 from the NIDCR, USA (PI, David Pashley). The authors are grateful to Michelle Barnes for secretarial support.

\section{REFERENCES}

Boston DW (2003). New device for selective dentin caries removal. Quintessence Int 34:678-685.

Carvalho RM, Pegoraro TA, Tay FR, Pegoraro LF, Silva NR, Pashley DH (2004). Adhesive permeability affects coupling of resin cements that utilise self-etching primers to dentine. J Dent 32:55-65.

Carvalho RM, Chersoni S, Frankenberger R, Pashley DH, Prati C, Tay FR (2005). A challenge to the conventional wisdom that simultaneous etching and resin infiltration always occurs (sic) in self-etch adhesives. Biomaterials 26:1035-1042.

Cheong C, King NM, Pashley DH, Ferrari M, Toledano M, Tay FR (2003). Incompatibility of self-etch adhesives with chemical/dualcured composites: two-step $v s$ one-step systems. Oper Dent 28:747-755.

Chersoni S, Suppa P, Grandini S, Goracci C, Monticelli F, Yiu C, et al. (2004). In vivo and in vitro permeability of one-step self-etch adhesives. J Dent Res 83:459-464.

Daculsi G, LeGeros RZ, Jean A, Kerebel B (1987). Possible physicochemical processes in human dentin caries. J Dent Res 66:13561359.

De Munck J, Van Landuyt K, Coutinho E, Poitevin A, Peumans M, Lambrechts P, et al. (2005). Micro-tensile bond strength of adhesives bonded to class-I cavity-bottom dentin after thermocycling. Dent Mater (in press).

Elgalaid TO, Youngson CC, McHugh S, Hall AF, Creanor SL, Foye RH (2004). In vitro dentine permeability: the relative effect of a dentine bonding agent on crown preparations. J Dent 32:413-421.

Goodis HE, Tao L, Pashley DH (1990). Evaporative water loss from human dentine in vitro. Arch Oral Biol 35:523-527.

Hashimoto M, De Munck J, Ito S, Sano H, Kaga M, Oguchi H, et al. (2004a). In vitro effect of nanoleakage expression on resin-dentin bond strengths analyzed by microtensile bond test, SEM/EDX and TEM. Biomaterials 25:5565-5574.

Hashimoto M, Ito S, Tay FR, Svizero NR, Sano H, Kaga M, et al. (2004b). Fluid movement across resin-dentin interface during and 
after bonding. J Dent Res 83:843-848.

Lee KW, Son HH, Yoshiyama M, Tay FR, Carvalho RM, Pashley DH (2003). Sealing properties of a self-etching primer system to normal caries-affected and caries-infected dentin. Am J Dent 16(Spec No):68A-72A.

Marshall GW, Habelitz S, Gallagher R, Balooch M, Balooch G, Marshall SJ (2001). Nanomechanical properties of hydrated carious human dentin. J Dent Res 80:1768-1771.

Matthews WG, Showman CD, Pashley DH (1993). Air blast-induced evaporative water loss from human dentine, in vitro. Arch Oral Biol 38:517-523.

Moszner N, Zeuner F, Fischer UK, Rheinberger V (1999). Monomers for adhesive polymers, 2. Synthesis and radical polymerization of hydrolytically stable acrylic phosphonic acids. Macromol Chem Phys 200:1062-1067.

Nishiyama N, Suzuki K, Yoshida H, Teshima H, Nemoto K (2004). Hydrolytic stability of methacrylamide in acidic aqueous solution. Biomaterials 25:965-969.

Pashley DH, Depew DD (1986). Effects of the smear layer, Copalite and oxalate on microleakage. Oper Dent 11:95-102.

Pashley DH, Michelich V, Kehl T (1981). Dentin permeability: effects of smear layer removal. J Prosthet Dent 46:531-537.

Pashley DH, Tay FR, Yiu C, Hashimoto M, Breschi L, Carvalho RM, et al. (2004). Collagen degradation by host-derived enzymes during aging. J Dent Res 83:216-221.

Sidhu SK, Agee KA, Waller JL, Pashley DH (2004). In vitro evaporative $v s$. convective water flux across human dentin before and after conditioning and placement of glass-ionomer cements. Am J Dent 17:211-215.

Suh BI, Feng L, Pashley DH, Tay FR (2003). Factors contributing to the incompatibility between simplified-step adhesives and chemically-cured or dual-cured composites. Part III. Effect of acidic resin monomers. J Adhes Dent 5:267-282.

Tay FR, Pashley DH (2003). Water treeing-a potential mechanism for degradation of dentin adhesives. Am J Dent 16:6-12.

Tay FR, Moulding KM, Pashley DH (1999). Distribution of nanofillers from a simplified-step adhesive in acid-conditioned dentin. $J$ Adhes Dent 2:103-117.

Tay FR, Pashley DH, Yiu CK, Sanares AM, Wei SH (2003a). Factors contributing to the incompatibility between simplified-step adhesives and chemically-cured or dual-cured composites. Part I. Single-step self-etching adhesive. J Adhes Dent 5:27-40.

Tay FR, Pashley DH, Peters MC (2003b). Adhesive permeability affects composite coupling to dentin treated with a self-etch adhesive. Oper Dent 28:610-621.

Tay FR, Frankenberger R, Krejci I, Bouillaguet S, Pashley DH, Carvalho RM, et al. (2004a). Single-bottle adhesives behave as permeable membranes after polymerization. I. In vivo evidence. $J$ Dent 32:611-621.

Tay FR, Pashley DH, Suh B, Carvalho R, Miller M (2004b). Singlestep, self-etch adhesives behave as permeable membranes after polymerization. Part I. Bond strength and morphologic evidence. Am J Dent 17:271-278.

Van Landuyt K, De Munck J, Snauwaert J, Coutinho E, Poitevin A, Yoshida Y, et al. (2005). Monomer-solvent phase separation in one-step self-etch adhesives. J Dent Res 84:183-188.

Yoshiyama M, Tay FR, Doi J, Nishitani Y, Yamada T, Itou K, et al. (2002). Bonding of self-etch and total-etch adhesives to carious dentin. J Dent Res 81:556-560.

Zheng L, Hilton JF, Habelitz S, Marshall SJ, Marshall GW (2003). Dentin caries activity status related to hardness and elasticity. Eur J Oral Sci 111:243-252. 